\title{
Probing the Antagonistic Effect of Toluene as a Component in Surrogate Fuel Models at Low Temperatures and High Pressures. A Case Study of Toluene/Dimethyl Ether Mixtures
}

Yingjia Zhang ${ }^{\mathrm{a}, \mathrm{b}^{*}}$, Kieran P. Somers ${ }^{\mathrm{a}, \mathrm{c}}$, Marco Mehl ${ }^{\mathrm{d}}$, William J. Pitz ${ }^{\mathrm{d}}$, Roger F. Cracknell ${ }^{\mathrm{c}}$, Henry J. Curran ${ }^{\mathrm{a}}$

a. Combustion Chemistry Centre, National University of Ireland, Galway, Ireland.

b. State Key Laboratory of Multiphase Flow in Power Engineering, Xi' an Jiaotong University, Xi'an 710049, China;

c. Shell Global Solutions, UK.

d. Lawrence Livermore National Laboratory, Livermore, CA 94550, USA.

\section{Abstract}

There is a dearth of experimental data which examine the fundamental low-temperature ignition $(T<900 \mathrm{~K})$ behavior of toluene resulting in a lack of data for the construction, validation, and interpretation of chemical kinetic models for commercial fuels. In order to gain a better understanding of its combustion chemistry, dimethyl ether (DME) has been used as a radical initiator to induce ignition in this highly knock resistant aromatic, and its influence on the combustion of toluene ignition was studied in both shock tube and rapid compression machines as a function of temperature $(624-1459 \mathrm{~K})$, pressure $(20-40 \mathrm{~atm})$, equivalence ratio $(0.5-2.0)$, and blending ratio (100\% toluene, $76 \%$ toluene (76T/24D), 58\% toluene (58T/42D), 26\% toluene (26T/74D) and 100\% DME)

Several literature chemical kinetic models are used to interpret our experimental results. For mixtures containing high concentrations of toluene at low-temperatures none of these are capable of reproducing experiment. This implies an incomplete understanding of the low-temperature oxidation pathways which control its ignition in our experimental reactors, and by extension, in spark- (SI) and compression-ignition (CI) engines, and an updated detailed chemical kinetic model is presented for engineering applications. 
Model analyses indicate that although the initial fate of the fuel is dominated by single-step H-atom abstraction reactions from both the benzylic and phenylic sites, the subsequent fate of the allylic and vinylic radicals formed is much more complex. Further experimental and theoretical endeavors are required to gain a holistic qualitative and quantitative chemical kinetics based understanding of the combustion of pure toluene, toluene blends, and commercial fuels containing other aromatic components, at temperatures of relevance to SI and CI engines.

Keywords: Shock tube; Rapid compression machine; Ignition delay time; Toluene; Dimethyl ether 


\section{Introduction}

Mono-aromatic hydrocarbons (MAH) such as toluene represent an important class of compounds found in commercially available gasoline, diesel, and jet fuels, and are key intermediates in the formation and growth of poly-aromatic hydrocarbons (PAHs) - known precursors of soot and particulate matter emissions from practical combustors.

However, the use of MAHs can offer combustion performance and efficiency benefits, specifically, those associated with increased anti-knock quality and fuel economy. A fuel's anti-knock quality is both legally and academically defined via its experimentally measured research (RON) and motor (MON) octane numbers. Toluene, RON of 120 and MON of 109 [1, 2], is extremely knock resistant when compared with iso-octane $(\mathrm{RON}=\mathrm{MON}=100)$, and with retail gasoline fuels, which typically have values ranging from the mid 80's for MON and mid 90's for RON [3].

Like toluene, market gasoline fuels typically display octane sensitivity, $S$, defined as the difference between the measured RON and MON values. It is well-established that an experimental or computational approach, which uses only primary reference fuels (PRFs) to quantify knock quality, will fail to capture the ignition behavior of the complex gasoline blends.

Higher-order blends of aromatics, olefins, paraffins, naphthenes, and oxygenates now form the basis of gasoline surrogate fuel formulations, and thus the detailed chemical kinetics based models used to numerically interpret fundamental and applied combustion experiments $[4,5]$. Conditions in SI engines are also diverging from those found in co-operative fuels research (CFR) engines due to novel technologies which aim to increase combustor performance and reduce emissions [6]. This again reduces the relevance of PRF blends in CFR engines to real-fuel combustion in modern engines.

The motivation for this work stems from a preliminary effort to computationally extrapolate the 
RON and MON ratings of some toluene reference fuels (TRFs) [7], to the conditions of a highly-boosted downsized direct-injection SI engine [8]. Order-of-magnitude differences in the ignition delay times $(\tau)$ of toluene-air mixtures were noted below $900 \mathrm{~K}$, as predicted by a range of available chemical kinetic models [4, 9-13], Fig. 1 and Fig. S29.

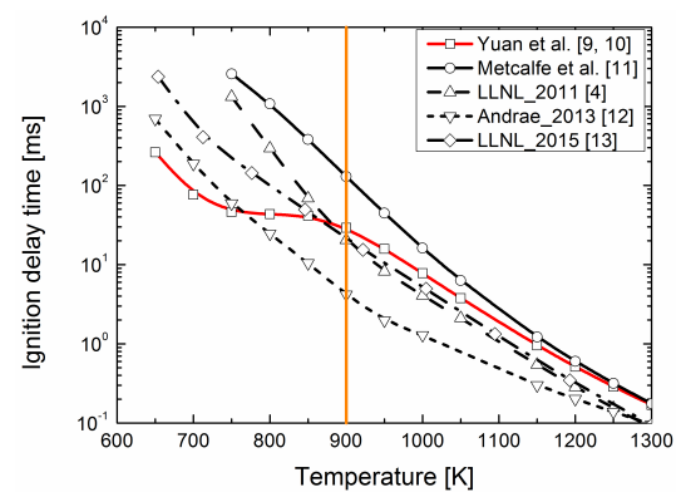

Figure 1. Simulated ignition delay times of stoichiometric toluene/air mixture at 20 atm with five mechanisms from literatures [4, 9-13].

Notably, the most recently published mechanism for toluene oxidation $[9,10]$ predicts a negative-temperature coefficient (NTC) regime at temperatures below $900 \mathrm{~K}$, a finding at odds with current thinking that high-sensitivity fuel components do not display the NTC behavior typical of observed in paraffinic fuels.

It would appear that researchers have not reached consensus with respect to the quantitative low-temperature oxidation (LTO) behavior of toluene, with a lack of experimental data on its gas-phase oxidation at temperature of relevance to RON/MON contributing to the problem. A recently validated model [9, 10] shows excellent agreement with available flow reactor [14], jet-stirred reactor $[15,16]$, shock tube [17-21], rapid compression machine (RCM) [22], and flame [23-27] data. However, none of these experiments probe toluene's LTO in detail below $873 \mathrm{~K}$, probably a result of its stability at low temperatures, and some sort of radical initiator is likely required to probe its LTO kinetics.

Several previous studies have investigated the combustion chemistry of toluene/ $n$-heptane 
mixtures at temperatures $(T)$, pressures $(p)$ and equivalence ratios $(\varphi)$ relevant to practical combustors $[4,28]$. However, the presence of $n$-heptane complicates the interpretation of underlying chemical kinetic information, due to the number of species and reactions needed to account for the presence of the $n$-paraffin computationally. The reduced number of thermochemical kinetic parameters required to predict DME ignition behavior in comparison to $n$-heptane should simplify the interpretation of our new experiments via computational models.

This study aims to contribute to the long-term resolution of the discrepancies shown in Fig. 1 by (a) providing new experimental evidence to identify whether NTC behavior exists as part of toluene's LTO, and (b) to identify key elementary reactions which control ignition delay time in order to focus the refinement of input parameters in available models.

\section{Experimental methodology}

\subsection{High-pressure shock tube}

All high temperature experiments were carried out in the NUIG high-pressure shock tube (HPST), as described previously [29]. The test mixtures were prepared in a stainless steel vessel which was heated to $80{ }^{\circ} \mathrm{C}$ within $\pm 3.5{ }^{\circ} \mathrm{C}$ of preset value and then were static for at least 12 hours prior to experiments to ensure sufficient evaporation and mixing. In previous studies of toluene ignition in shock tubes [21], the authors observed that contamination from its combustion can significantly influence measured ignition times. However, pre-ignition energy release is observed in some of the current experiments even when the HPST was cleaned using acetone or ethanol, consistent with the study of Davidson et al. [19]. We do not include these experiments when assessing model performance. Detail pressure histories are presented in Figs. S1, S2. 


\subsection{Rapid compression machine}

All experiments at low to intermediate temperatures were performed in an RCM described by Darcy et al. [30]. Similar to Mittal and Sung [22], to minimize the effect of soot deposits caused by toluene combustion, three pure oxygen experiments were performed after each experiment. We found that this procedure was sufficient to obtain good repeatability, with no obvious pre-ignition observed, Figs. S3, S4.

Toluene (99.0\%) and DME (99.9\%) were obtained from Sigma-Aldrich, while helium (99.9\%), oxygen (99.5\%), argon (99.9995\%), nitrogen (99.95\%), and carbon dioxide (99.5\%) were supplied by BOC Ireland. Auto-ignition measurements for toluene/DME/“air" mixtures were conducted at temperatures of $624-1459 \mathrm{~K}$, pressures of $20-40 \mathrm{~atm}$, and equivalence ratios of $0.5-2.0$. Table S1 lists the detailed composition of the fourteen test mixtures studied.

\section{Numerical simulations}

Four mechanisms, named NUIG-Metcalfe, NUIG-Yuan, LLNL_2015 [13] and TestMech, were used to interpret experiment. For the NUIG-Metcalfe and NUIG-Yuan mechanisms, the toluene sub-models are adopted directly from Metcalfe et al. [11] and Yuan et al. [9, 10], while the core and DME mechanisms are adopted from Burke et al. [31]. In the LLNL_2015 mechanism, we have taken the mechanism unchanged as it already contains recent iterations of the NUIG core chemistry. For the updated model presented herein, TestMech, the $\mathrm{C}_{0}-\mathrm{C}_{4}$ mechanism is adopted from the NUIG library [32-34], while the toluene sub-model is largely from the recent LLNL_2015 mechanism.

Revisions have been made to the TestMech, including new reaction classes and updated ones, as tabulated in Table $\mathrm{S} 2$ of the Supplemental material. The most important revisions made to better predict our new experiments include minor alterations to the reactions of toluene with $\dot{O} H$ [35] and $\mathrm{O}_{2}$ [36], and an updated estimate for the recombination of benzyl radicals [37]. We have also updated 
rate constants for the important $\mathrm{C}_{6} \mathrm{H}_{5} \dot{\mathrm{C}} \mathrm{H}_{2}+\mathrm{HO}_{2}$ reaction pathway based on the original work of $d a$ Silva and Bozzelli [38], with an assessment of the pressure-dependencies of each pathway carried out using Quantum-Rice-Ramsperger-Kassel theory [39] with a modified strong collision approximation accounting for collisional energy transfer. The approach has been shown to compare well with more accurate/expensive Rice-Ramsperger-Kassel-Marcus/Master-Equation simulations for one-well systems in the past [40]. The Comprehensive kinetic mechanism TestMech and thermochemistry files is available as the Supplementary Material.

These revisions were carried out based on insight gathered from rate-of-production (ROP) and sensitivity analyses (SA), which will be used to guide subsequent discussions. All simulations were carried out using the Aurora module of CHEMKIN-PRO [41] with constant volume conditions for the HPST experiments and with facility effects incorporated for the RCM results as described in Darcy et al. [30].

\section{Results and discussion}

Ignition delay times were measured for fourteen mixtures as a function of $T, p, \varphi$, and blending ratio, in two independent facilities. Thus, the data represents an extensive and reliable experimental database for toluene ignition over a comprehensive range of conditions relevant to combustors. There are also an abundance of trends to analyze and systematic comparisons of model predictions and measurements are provided in Figs. S5-S14 and Table S3 as Supplemental material.

The focus of this discussion will be on the influence of toluene/DME blending ratio on the LTO of the title fuels, Fig. 2, as it provides fundamental insight into the LTO of pure toluene, and into component interactions in more complex real-fuel mixtures under ignition-relevant conditions in modern transportation engines. The NUIG-Metcalfe model was ultimately chosen to illustrate the improved predictions of the updated TestMech model, as the former provided the best agreement of 
the literature models with our new experiments. Predictions of other mechanisms are provided in Fig. S5-S7, with both the NUIG-Yuan and LLNL_2015 mechanisms found to consistently under-predict experiment in the LTO regime of our new experiments.
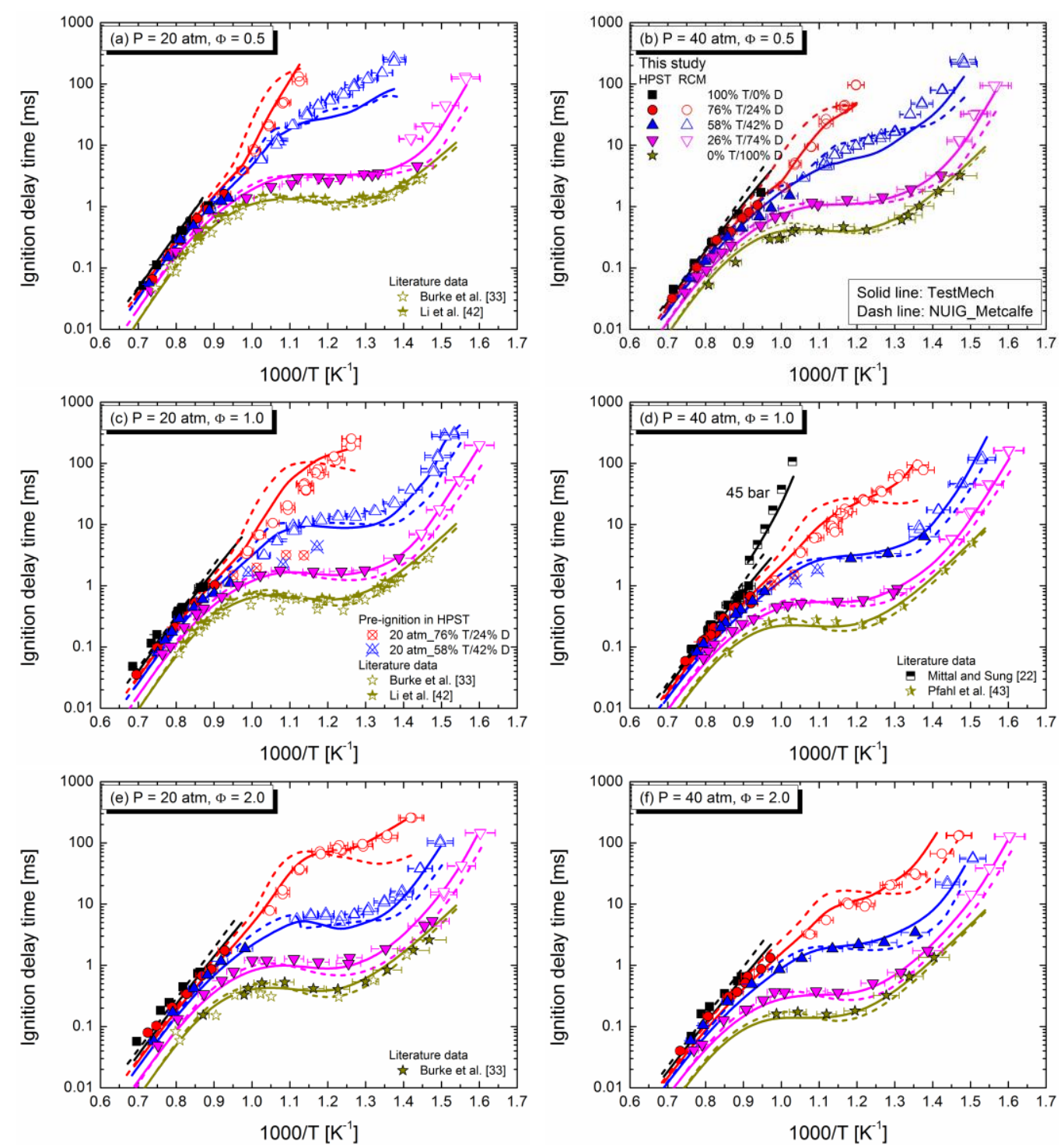

Figure 2. Effect of varying blending ratio on the reactivity of toluene/DME mixtures with the simulation comparison of TestMech and NUIG-Metcalfe.

\subsection{Effect of temperature, pressure, and equivalence ratio on ignition delay time of pure fuels}

For a given pure-mixture, the experimental trends with respect to the influence of $T, p$ and $\varphi$ on $\tau$ are in-line with past-studies, and will not be discussed in great detail. For $100 \%$ toluene/air mixtures the experimental dependence of $\tau$ on $T$ follows simple Arrhenius behavior for a given $p / \varphi$ for the HPST measurements from 1000 - $1459 \mathrm{~K}$. For the 100\% DME/air mixtures, ignition delay 
times have been measured in the HPST from $681-1148 \mathrm{~K}$, at $\varphi=0.5(40 \mathrm{~atm})$ and $2.0(20 / 40 \mathrm{~atm})$ in order to audit our experimental protocol through comparison with previous literature [31, 42, 43], and to expand upon the $T / p / \varphi$ ranges where measurements exist for DME. Collated, the measurements span the ranges of $664-1341 \mathrm{~K}, 20-40$ atm, and $\varphi=0.5-2.0$, with DME's well-known NTC regime visible at each $p / \varphi$. With the adoption of the Burke et al. [31] DME mechanism, all of the current models are shown to recreate this behavior quite well.

The assembled models show validity in predicting $\tau$ for each pure fuel, within temperature and pressure regimes where their ignition can be measured in isolation. The fundamental question of this work now arises - is this validity retained, and hence our understanding of the underling combustion mechanism, when we model $\tau$ for mixtures with high concentrations of toluene at temperatures lower?

\subsection{Low temperature effect of blending ratio and controlling reactions}

As a result of DME's LTO pathways, its addition has a significant influence on the ignition properties of toluene at temperatures below $1000 \mathrm{~K}$, Fig. 2. For mixtures with $\leq 26 \%$ toluene, all of the kinetic models can reproduce the experiments at low-temperatures, as $\tau$ is controlled by DME LTO.

However, for mixtures with $\geq 58 \%$ toluene, the literature models have difficulty in reproducing experiment, as expected based on results in Fig. 1. Indeed, the biggest deviations are found when simulating the 76T/24D mixtures which extend below the temperatures of past experimental studies, into the regimes where current toluene models are shown to disagree. The experiments also show that the $76 \mathrm{~T} / 24 \mathrm{D}$ mixtures do not produce NTC ignition behavior, meaning global ignition is controlled more by toluene rather than DME. The overwhelming conclusion is that the NTC behavior observed in literature models is not based in physical reality, owing to deficiencies in model 
input parameters when modelling combustor relevant experiments.

As part of the refinements to existing models, we have introduced some potentially important reactions including cross reactions between DME and toluene-derived radicals, and ÓH-toluene addition reactions which are known to be important for lower-order olefins [44]. We find that these new reaction pathways have little or no effect on the reactivity of toluene/DME mixtures, Section S3. The inability of the available mechanisms to predict the new experiments is likely a result of uncertainties in the chemical kinetics and thermodynamics in pre-existing pathways in these models, or the result of other missing pathways which we do not speculate on as of yet. Hence the need to make revisions to existing pathways as described in Table S2 in order to replicate the experiments.

The ROP (Fig. 3 and Figs. S17-20) and SA (Fig. S21) analyses highlight that the dominant pathways for toluene consumption are a promoting/inhibiting competition between the abstractions of a benzylic/phenylic $\mathrm{H}$-atom by $\mathrm{O} H$ radicals. These pathways are not perturbed by DME addition to a great extent.

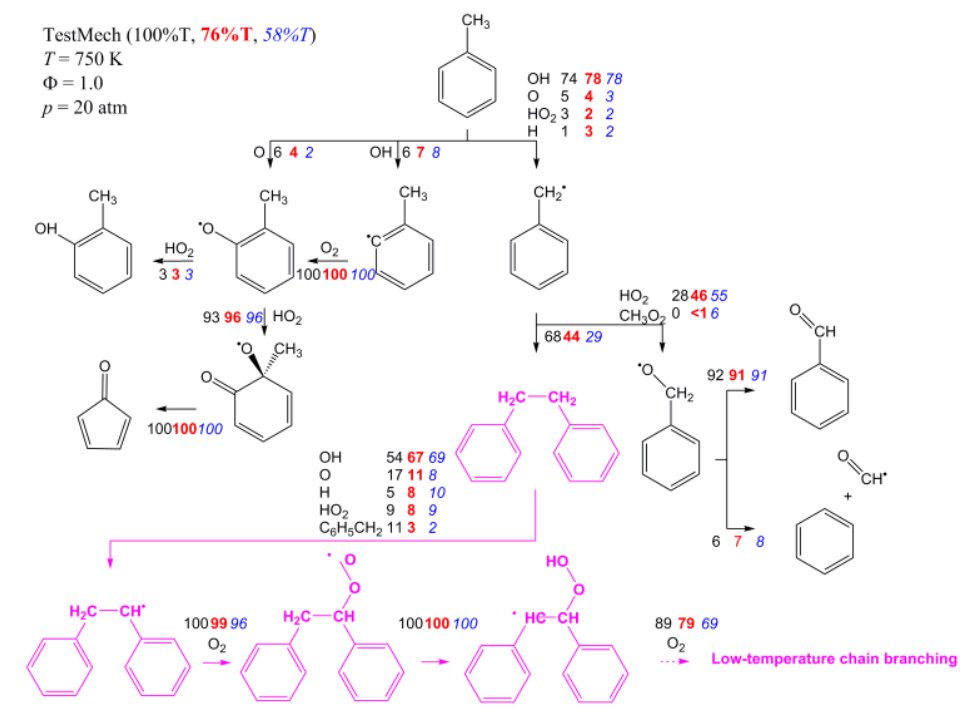

Figure 3. Flux analysis on toluene oxidation at $p=20$ atm, $T=750 \mathrm{~K}, \varphi=1.0$ and $20 \%$ fuel consumption for various toluene/DME blends.

However, the fate of the benzyl radical $\left(\mathrm{C}_{6} \mathrm{H}_{5} \dot{\mathrm{C}} \mathrm{H}_{2}\right)$ formed via abstraction is influenced by DME addition. For the $100 \%$ toluene, $76 \mathrm{~T} / 24 \mathrm{D}$ and $58 \mathrm{~T} / 42 \mathrm{D}$ mixtures, the promoting-reactions of 
$\mathrm{C}_{6} \mathrm{H}_{5} \dot{\mathrm{C}} \mathrm{H}_{2}$ with $\mathrm{HO}_{2}$ (all pathways ultimately form $\mathrm{C}_{6} \mathrm{H}_{5} \mathrm{CH}_{2} \dot{\mathrm{O}}$ and an $\dot{\mathrm{O}} \mathrm{H}$ radical), account for $28 \%$, $46 \%$ and $55 \%$ of the consumption of $\mathrm{C}_{6} \mathrm{H}_{5} \dot{\mathrm{C}} \mathrm{H}_{2}$, respectively, in TestMech.

Relatively speaking, these $\mathrm{C}_{6} \mathrm{H}_{5} \dot{\mathrm{C}} \mathrm{H}_{2}+\mathrm{RO}_{2}$ reactions increase reactivity of pure-toluene, as they are in direct competition with the chain-terminating self-recombination of $\mathrm{C}_{6} \mathrm{H}_{5} \dot{\mathrm{C}} \mathrm{H}_{2}$ to form bi-benzyl $\left(\mathrm{C}_{14} \mathrm{H}_{14}\right)$, a reaction which consumes $68 \%, 44 \%$ and $29 \%$ of $\mathrm{C}_{6} \mathrm{H}_{5} \dot{\mathrm{C}} \mathrm{C}_{2}$ radicals for the $100 \%$ toluene, $76 \mathrm{~T} / 24 \mathrm{D}$ and $58 \mathrm{~T} / 42 \mathrm{D}$ mixtures respectively. In contrast, this reaction was much less important, consuming only $29 \%, 13 \%$ and $1 \%$ of $\mathrm{C}_{6} \mathrm{H}_{5} \dot{\mathrm{C}} \mathrm{H}_{2}$ radicals at $1250 \mathrm{~K}$ for the $100 \%, 76 \%$ and $58 \%$ toluene mixtures, Fig. S17.

It appears that in the absence of radicals which can readily oxidize $\mathrm{C}_{6} \mathrm{H}_{5} \dot{\mathrm{C}} \mathrm{H}_{2}$ radicals, (e.g. Ö, $\mathrm{HO}_{2}, \mathrm{CH}_{3} \dot{\mathrm{O}}_{2}$ ) alternative chain-termination reactions will understandably inhibit LTO. Similar trends are known for other olefins [33, 34]. Along with this increased tendency for $\mathrm{C}_{6} \mathrm{H}_{5} \dot{\mathrm{C}} \mathrm{H}_{2}$ radicals to undergo an inhibiting self-recombination, is a decrease in the predictive ability of all literature mechanisms. The two are not necessarily correlated, but this may point to a lack of fundamental understanding of some critical chemical processes involving toluene-derived radicals and their LTO.

$\mathrm{C}_{14} \mathrm{H}_{14}$ mainly preferentially undergoes abstraction of a secondary-allylic- $\mathrm{H}$ atom followed by addition of the $\dot{\mathrm{C}}_{14} \mathrm{H}_{13}$ radical to $\mathrm{O}_{2}$ forming a peroxyl radical, which can then isomerize and undergo a second addition to $\mathrm{O}_{2}$ in a "typical" paraffinic LTO sequence leading to chain-branching, Fig. 3. Whilst $\mathrm{C}_{6} \mathrm{H}_{5} \dot{\mathrm{C}} \mathrm{H}_{2}$ radicals undergo oxidation by reaction with $\mathrm{HO}_{2}$ radicals, they are entirely resistant to reaction with $\mathrm{O}_{2}$. Conversely, the analogous radical formed from $\mathrm{C}_{14} \mathrm{H}_{14}$ is almost entirely oxidized by $\mathrm{O}_{2}$, with limited reaction with $\mathrm{HO}_{2}$.

Both Metcalfe et al. [11] and Yuan et al. [10] validated their kinetic estimates for these pathways against speciation data which quantified $\mathrm{C}_{14} \mathrm{H}_{14}$ and its product stilbene $\left(\mathrm{C}_{14} \mathrm{H}_{12}\right)$, but these data were at higher temperatures than herein. Metcalfe et al. noted that no typical LTO pathways were 
occurring in their experiments, based upon interpretation using their model. Here we show that the thermodynamic/rate-constant estimates employed by Metcalfe et al. leads to this pathway being important in the consumption of $\mathrm{C}_{14} \mathrm{H}_{14}$, whose combustion chemistry is virtually unknown, as a critical intermediate in toluene LTO.

Interpretation using the NUIG_Yuan mechanism (Fig. S19) shows an entirely different behavior to other models, the dominant consumption pathway of $\mathrm{C}_{6} \mathrm{H}_{5} \dot{\mathrm{C}} \mathrm{H}_{2}$ occurring via reaction with $\mathrm{HO}_{2}$ to form $\mathrm{C}_{6} \mathrm{H}_{5} \mathrm{CH}_{2} \mathrm{O}$ via a chemically activated process $(65 \%)$, or, formation of $\mathrm{C}_{6} \mathrm{H}_{5} \mathrm{CH}_{2} \dot{\mathrm{O}}_{2}$ through addition to $\mathrm{O}_{2}(22 \%)$. The absence of a bi-benzyl formation pathway is notable.

Also of note in the NUIG_Yuan mechanism is that numerous key reactions of $\mathrm{C}_{6} \mathrm{H}_{5} \dot{\mathrm{C}} \mathrm{H}_{2}$ radicals are estimated with pressure-dependent rate constants defined to a maximum pressure of 10 Torr, which we anticipate induces fall-off behavior in these reactions despite the fact that high-pressure limiting behavior is more likely under our experimental conditions, and in practical combustors. Compared to other models, the under-prediction of $\tau$ by the NUIG_Yuan mechanism is likely centered around uncertainties in the reactions of $\mathrm{C}_{6} \mathrm{H}_{5} \dot{\mathrm{C}} \mathrm{H}_{2}$ radical.

The analyses carried out clearly illustrate a lack of agreement amongst available models, which has numerous consequences with respect to available models for TRF blends. We have therefore combined TestMech with an $n$-heptane mechanism that has been widely validated at NUIG [45] in order to simulate $\tau$ for some gasoline surrogate fuels, as measured by Herzler et al. [28], Fig 4, and by Hartmann et al. [46], Fig. S28. The modified toluene mechanism is capable of reproducing experimental data for these surrogates which contain the higher-order hydrocarbons found in gasoline fuels making the model a valid candidate for amalgamation into detailed gasoline surrogate mechanisms. 


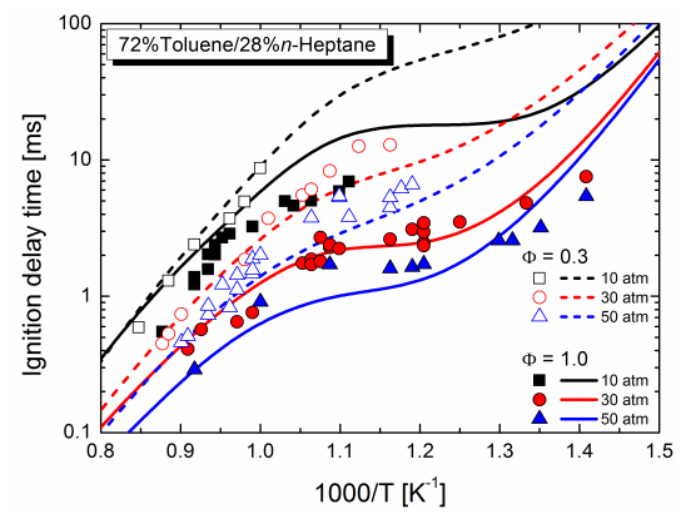

Figure 4. Comparison of shock tube data from Herzler et al. [28] and TestMech simulations for toluene/ $n$-heptane mixtures.

\subsection{Further Implications for Modelling of "Allylic” Hydrocarbons and Commercial Fuels}

Insight gathered from our combined experimental/modelling approach have allowed us to better understand the LTO of toluene, and by extension, the reactions which lead to octane benefits from the presence of aromatic and other "allylic" hydrocarbons in commercial fuels. From the perspective of a fuels-blend scientist using toluene's antagonistic quality to improve the anti-knock rating of a generic real-fuel formulation, the critical reaction steps can be summarized as follows.

It appears that some of the free radicals generated from the LTO of the higher-cetane/lower-octane component, in this case DME, will be scavenged by toluene, preferentially forming either the resonantly-stabilized $\mathrm{C}_{6} \mathrm{H}_{5} \dot{\mathrm{C}} \mathrm{H}_{2}$ radicals or the vinylic methyl-phenyl $\left(\dot{\mathrm{C}}_{6} \mathrm{H}_{4} \mathrm{CH}_{3}\right)$ radical.

Unlike $\dot{\mathrm{C}}_{6} \mathrm{H}_{4} \mathrm{CH}_{3}$ and $\mathrm{CH}_{3} \mathrm{O} \dot{\mathrm{C}} \mathrm{H}_{2}$ radicals, the $\mathrm{C}_{6} \mathrm{H}_{5} \dot{\mathrm{C}} \mathrm{H}_{2}$ radical is highly-stable with respect to oxidation by $\mathrm{O}_{2}$, which is typically one of the global rate limiting steps in LTO reactions, and hence there is no rapid mechanism via which chain-propagation or branching can occur when $\mathrm{C}_{6} \mathrm{H}_{5} \dot{\mathrm{C}} \mathrm{H}_{2}$ is the dominant abstraction product. If the temperature is insufficient to pyrolyze $\mathrm{C}_{6} \mathrm{H}_{5} \dot{\mathrm{C}} \mathrm{H}_{2}$ radicals, they will be consumed by reaction with $\mathrm{RO}_{2}$ radicals, but this step is limited by a) the concentration of $\mathrm{RO}_{2}$ radicals in the system and their relative reactivity, and b) the quantity of $\mathrm{C}_{6} \mathrm{H}_{5} \dot{\mathrm{C}} \mathrm{H}_{2}$ which self-terminates forming $\mathrm{C}_{14} \mathrm{H}_{14}$. 
We have found that the importance of the former reaction increases with increasing DME content in the mixture, meaning that the relative decrease in toluene ignition delay time as a function of increasing DME content is not solely a result of a total increase in radical production via DME LTO, but also, addition of DME decelerates the rate of formation of bi-benzyl due to accelerated $\mathrm{HO}_{2}$ production rates. Interestingly, whilst DME addition perturbs the natural reaction flux of toluene, it does not obscure the chemical kinetics of relevance to the aromatic; rather we find an increased sensitivity of some important rate parameters in the toluene system upon addition of DME, Fig. S21.

Irrespective of whether it is the oxidation or termination reaction which consumes benzyl radicals, both will contribute to inhibition of ignition times for the lower-octane component, as in the absence of toluene as a fuel component this scavenging would not occur and free radicals would be free to react with the higher-cetane/lower-octane component leading to reduced ignition times.

More succinctly, toluene's ability to act as a radical sink/anti-knock agent can be traced to its weak allylic C-H bond, the subsequent reactions of $\mathrm{C}_{6} \mathrm{H}_{5} \dot{\mathrm{C}} \mathrm{H}_{2}$ radical, and ultimately, the lack of a rapid oxidation mechanism for the latter at temperatures of relevance to auto-ignition in SI engines.

\section{Conclusions}

Ignition delay times for toluene/dimethyl ether/air blends have been measured for the first time in shock tube and RCM facilities under a wide-range of conditions of relevance to automotive engines. Dimethyl ether was preferred to $n$-heptane a surrogate for the low-octane components typically found in gasoline fuels, as it offers advantages over the latter in terms of our experimental procedure (higher vapor pressure, less soot), and subsequent interpretation of the results via detailed kinetic models.

No available literature mechanisms can predict the ignition behavior of these mixtures over the complete range of temperatures, pressures, equivalence ratios, and blending ratios studied. We find 
that with increasing toluene concentration and decreasing temperature, the accuracy of the computational results worsens, as the chemical kinetics and thermodynamic estimates of the toluene sub-mechanism become increasingly uncertain.

This work has allowed us to gain critical insight into the LTO of toluene/toluene-blends based on interpretation of these models. Asides from a new experimental database, a key outcome of the current work is an updated chemical kinetic model which is better able to predict the antagonistic effect of toluene on more reactive components, and the updated model can be used in gasoline surrogate fuel formulations without the need for major revisions to existing surrogates.

Unfortunately, those who yearn for a "chemically accurate" model for toluene LTO must look beyond the horizon towards the numerous experimental and theoretical studies which will be required to meet this aim. Based on our findings we make the following recommendations for future studies:

1. There are few studies which quantify intermediates from toluene oxidation at temperatures below $900 \mathrm{~K}$, and at pressures of relevance to SI/CI engines. Jet-stirred/flow reactor studies on toluene/DME blends should allow for this. We do not advocate for the use of high-order alkanes as a radical initiator if probing the LTO of toluene is the aim of such a study.

2. Experimental/theoretical determinations of the temperature- and/or pressure-dependency of the reactions of $\dot{\mathrm{OH}}$ radicals, $\mathrm{O}$ atoms and $\mathrm{O}_{2}$ with toluene would be of value. No available "detailed" models have considered the complete site-specificity of these reactions-Ö atom addition reactions are currently "lumped", and only a single methyl-phenyl radical is present in current models. Similarly, high-level studies of the reactions of $\mathrm{C}_{6} \mathrm{H}_{5} \dot{\mathrm{C}} \mathrm{H}_{2}$ with $\mathrm{HO}_{2}$, and the reactions of methyl-phenyl and bi-benzyl radicals with $\mathrm{O}_{2}$ would serve to reduce uncertainty in important reaction pathways. 
3. Systematic combustion studies on bi-benzyl, benzaldehyde, phenol, cyclopentadieneone, and the isomers of cresol and benzoquinone, would allow for refinements in the secondary modules of available mechanisms, which, based on our findings for toluene, must be similarly uncertain.

\section{Acknowledgments}

The authors would like to thank the EU for his funding under the European Commission Marie Curie Transfer of Knowledge Scheme (FP7) pursuant to Contract PIAP-GA-2013-610897 GENFUEL. We would also like to acknowledge the support from the National Natural Science Foundation of China (No. 91541115). 


\section{References}

[1] J.B. Heywood, Internal Combustion Engine Fundamentals, Mcgraw-hill New York, 1988.

[2] N. Morgan, A. Smallbone, A. Bhave, M. Kraft, R. Cracknell, G. Kalghatgi, Combustion and Flame, 157 (2010) 1122-1131.

[3] S. Advisors, 2015 Global Fuel Specifications, Stratas Advisors, 2015.

[4] M. Mehl, W.J. Pitz, C.K. Westbrook, H.J. Curran, Proceedings of the Combustion Institute, 33 (2011) $193-200$.

[5] E. Ranzi, A. Frassoldati, A. Stagni, M. Pelucchi, A. Cuoci, T. Faravelli, International Journal of Chemical Kinetics, 46 (2014) 512-542.

[6] G.T. Kalghatgi, in, SAE Technical Paper, 2005.

[7] T.J. Davies, R.F. Cracknell, B. Head, K. Hobbs, T. Riley, in, SAE Technical Paper, 2011.

[8] K.P. Somers, R.F. Cracknell, H.J. Curran, in: 7 th European Combustion Meeting, Budapest, Hungary, 2015.

[9] W. Yuan, Y. Li, P. Dagaut, J. Yang, F. Qi, Combustion and Flame, 162 (2015) 22-40.

[10] W. Yuan, Y. Li, P. Dagaut, J. Yang, F. Qi, Combustion and Flame, 162 (2015) 3-21.

[11] W. Metcalfe, S. Dooley, F. Dryer, Energy \& Fuels, 25 (2011) 4915-4936.

[12] J. Andrae, Fuel, 107 (2013) 740-748.

[13] H. Nakamura, D. Darcy, M. Mehl, C.J. Tobin, W.K. Metcalfe, W.J. Pitz, C.K. Westbrook, H.J. Curran, Combustion and Flame, 161 (2014) 49-64.

[14] S.D. Klotz, K. Brezinsky, I. Glassman, in: Symposium (International) on Combustion, Elsevier, 1998, pp. 337-344.

[15] P. Dagaut, G. Pengloan, A. Ristori, Physical Chemistry Chemical Physics, 4 (2002) 1846-1854.

[16] R. Bounaceur, D. Costa, R. Fourent, F. Billaud, F. Battin-Leclerc, International journal of chemical kinetics, 37 (2005) 25-49.

[17] R. Sivaramakrishnan, R.S. Tranter, K. Brezinsky, The Journal of Physical Chemistry A, 110 (2006) 9388-9399.

[18] R. Sivaramakrishnan, R. Tranter, K. Brezinsky, Combustion and flame, 139 (2004) 340-350.

[19] D. Davidson, B. Gauthier, R. Hanson, Proceedings of the Combustion Institute, 30 (2005) 1175-1182.

[20] V. Vasudevan, D. Davidson, R. Hanson, Proceedings of the Combustion Institute, 30 (2005) 1155-1163.

[21] H.-P.S. Shen, J. Vanderover, M.A. Oehlschlaeger, Proceedings of the Combustion Institute, 32 (2009) $165-172$.

[22] G. Mittal, C.-J. Sung, Combustion and Flame, 150 (2007) 355-368.

[23] Y. Li, L. Zhang, Z. Tian, T. Yuan, J. Wang, B. Yang, F. Qi, Energy \& Fuels, 23 (2009) 1473-1485.

[24] V. Detilleux, J. Vandooren, Proceedings of the Combustion Institute, 33 (2011) 217-224.

[25] T. Hirasawa, C. Sung, A. Joshi, Z. Yang, H. Wang, C. Law, Proceedings of the Combustion Institute, 29 (2002) $1427-1434$.

[26] C. Ji, E. Dames, H. Wang, F.N. Egolfopoulos, Combustion and Flame, 159 (2012) 1070-1081.

[27] R. Johnston, J. Farrell, Proceedings of the combustion institute, 30 (2005) 217-224.

[28] J. Herzler, M. Fikri, K. Hitzbleck, R. Starke, C. Schulz, P. Roth, G. Kalghatgi, Combustion and flame, 149 (2007) 25-31.

[29] D. Darcy, C.J. Tobin, K. Yasunaga, J.M. Simmie, J. Wurmel, W.K. Metcalfe, T. Niass, S.S. Ahmed, C.K. Westbrook, H.J. Curran, Combustion and Flame, 159 (2012) 2219-2232.

[30] D. Darcy, H. Nakamura, C. Tobin, M. Mehl, W. Metcalfe, W. Pitz, C. Westbrook, H. Curran, Combustion and Flame, 161 (2014) 65-74.

[31] U. Burke, K.P. Somers, P. O'Toole, C.M. Zinner, N. Marquet, G. Bourque, E.L. Petersen, W.K. Metcalfe, Z. Serinyel, H.J. Curran, Combustion and Flame, 162 (2015) 315-330.

[32] W.K. Metcalfe, S.M. Burke, S.S. Ahmed, H.J. Curran, International Journal of Chemical Kinetics, 45 (2013) 638-675.

[33] S.M. Burke, U. Burke, R. Mc Donagh, O. Mathieu, I. Osorio, C. Keesee, A. Morones, E.L. Petersen, W. Wang, T.A. 
DeVerter, Combustion and Flame, 162 (2015) 296-314.

[34] S.M. Burke, W. Metcalfe, O. Herbinet, F. Battin-Leclerc, F.M. Haas, J. Santner, F.L. Dryer, H.J. Curran, Combustion and Flame, 161 (2014) 2765-2784.

[35] T. Seta, M. Nakajima, A. Miyoshi, The Journal of Physical Chemistry A, 110 (2006) 5081-5090.

[36] M.A. Oehlschlaeger, D.F. Davidson, R.K. Hanson, Combustion and flame, 147 (2006) 195-208.

[37] P.T. Lynch, C.J. Annesley, C.J. Aul, X. Yang, R.S. Tranter, The Journal of Physical Chemistry A, 117 (2013) 4750-4761.

[38] G. da Silva, J.W. Bozzelli, Proceedings of the Combustion Institute, 32 (2009) 287-294.

[39] A. Chang, J. Bozzelli, A. Dean, Zeitschrift für Physikalische Chemie International journal of research in physical chemistry and chemical physics, 214 (2000) 1533.

[40] M. Pelucchi, K.P. Somers, K. Yasunaga, U. Burke, A. Frassoldati, E. Ranzi, H.J. Curran, T. Faravelli, Combustion and Flame, 162 (2015) 265-286.

[41] C.-P. Release, Inc., San Diego, CA, (2010).

[42] Z. Li, W. Wang, Z. Huang, M.A. Oehlschlaeger, Energy \& Fuels, 27 (2013) 2811-2817.

[43] U. Pfahl, K. Fieweger, G. Adomeit, in: Symposium (International) on Combustion, Elsevier, 1996, pp. $781-789$.

[44] C. Zhou, Y. Li, E. O'Connor, K.P. Somers, S. Thion, C. Keesee, O. Mathieu, E.L. Petersen, T.A. DeVerter, M.A. Oehlschlaeger, G. Kukkadapu, P.-A. Glaude, F. Battin-Leclerc, J. Santner, Y. Ju, T. Held, F.M. Haas, F.L. Dryer, H.J. Curran, Combustion and Flame, In Review (2015).

[45] K. Zhang, C. Banyon, P.-A. Glaude, F. Battin-Leclerc, H.J. Curran, Combustion and Flame, in preparation (2015).

[46] M. Hartmann, I. Gushterova, M. Fikri, C. Schulz, R. Schie?1, U. Maas, Combustion and Flame, 158 (2011) $172-178$. 